\title{
Evaluation of Nigerian hospital meal carts
}

\author{
Sesan P. Ayodeji ${ }^{1} \cdot$ Michael K. Adeyeri $^{1} \cdot$ Olaoluwa Omoniyi $^{2}$
}

Received: 3 October 2014/Accepted: 5 March 2015/Published online: 24 March 2015

(c) The Author(s) 2015. This article is published with open access at Springerlink.com

\begin{abstract}
Hospital meal carts are used to deliver meals, drugs and some other materials to patients in the hospital environment. These carts which are moved manually by operators, the health workers, mostly do not comply with ergonomics guidelines and physical requirements of the equipment users in terms of anthropometry data of the region thus increasing the risk of musculoskeletal disorder among the meal cart users. This study carried out ergonomic evaluation of the available meal carts in some western Nigeria hospitals. A well-structured questionnaire has two major segments: Operational survey and biomechanical survey, which were administered to the health workers using hospital meal carts in some hospitals in southwestern Nigeria, and physical assessment, which was undertaken to collect data for the ergonomic evaluation. The responses from the questionnaires show that some areas on the existing hospital meal carts are of concern to the users which need to be improved upon.
\end{abstract}

Keywords Hospital $\cdot$ Nigeria $\cdot$ Meal cart $\cdot$ Ergonomics

Michael K. Adeyeri

adeyerimichaeltut@gmail.com; adeyerimk@tut.ac.za

Sesan P. Ayodeji

ayodejisesantut@gmail.com

1 Department of Industrial Engineering, Tshwane University of Technology, Pretoria, South Africa

2 Department of Mechanical Engineering, The Federal University of Technology, Akure, Nigeria

\section{Introduction}

Manual vehicles such as carts, hand trucks, wheel barrows and just to mention a few have been of great advantage to the transportation of materials due to the presence of wheels. Studies have shown that the use of manual vehicle is less stressful and more efficient than their nonuse material handlings (Schibyte et al. 2001). The use of carts in the hospital environments is a common feature as the need to move things here and there in the hospital is a common phenomenon. Hospital meal carts are used to deliver hot meals, breakfast, lunch and dinner on trays to the patients. These carts are moved manually by operators which are both males and females. Considerable pushing, pulling forces are involved in moving these hospital meal carts, also bending and lifting are also involved during the process of handling these meal carts. Considering this level of work, fatigue tends to set in on the workers before the end of the shift period. The workers tend to have increased rate of musculoskeletal disorder such as lower back pain, upper back pain, feeling of ache on the arms and increased rate of transfer of aggression due to fatigue, on the patients within their care. Figure 1 shows the picture of some of the hospital meal carts common to Nigeria hospitals that were evaluated.

Ergonomics is the science of fitting jobs to people. The discipline encompasses a body of knowledge about physical abilities and limitations as well as other human characteristics that are relevant to job design. Essentially, ergonomics is the relationship between the worker and the job and focuses on the design of work areas to enhance job performance. Ergonomics can help prevent injuries and limit secondary injuries as well as accommodate individuals with various disabilities, including those with musculoskeletal disorders (MSDs) (Beth et al. 2010). 


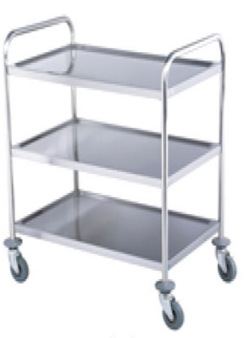

(a)

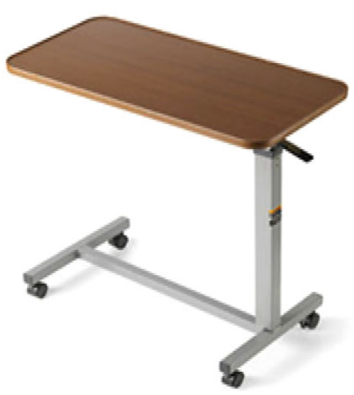

(c)

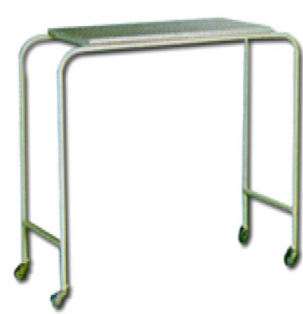

(b)

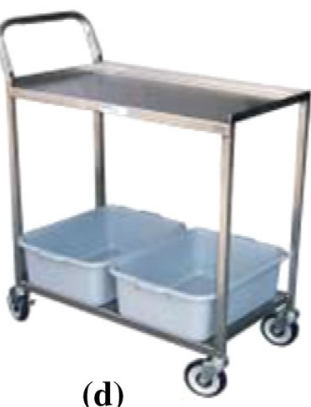

(d)
Fig. 1 Picture of some of the hospital meal carts common to Nigeria hospitals: a Three-layer hospital meal cart; b over bed table/meal cart; c over bed table/meal cart; $\mathbf{d}$ two-layer hospital meal cart

Statistics on pushing and pulling from Reporting of Injuries, Diseases and Dangerous Occurrences Regulations (RIDDOR) investigated by Health and Safety Executive (HSE) showed that the most frequently reported site of injury was the back (44\%), followed by the upper limbs (shoulder, arms, wrist and hand) accounting for $28.6 \%$, $12 \%$ for accidents involving pulling than pushing, $61 \%$ of accidents involving pushing and pulling objects that were not supported on wheels (bales, desks, etc.) and $35 \%$ of pushing and pulling accidents involving objects (Health and Safety Executive 2013). Also Jung et al. (2005) revealed that the use of hospital meal carts was designed to ease the burden of manual material handling on workers, and it has been shown to be efficient because of less energy used per time. However, recent studies reported that these carts have caused suffering and injuries to workers and has increased the risk of musculoskeletal problems.

This statistics shows that there is need to eliminate or reduce the risk factor associated with pulling and pushing. In the use of hospital meal cart, the posture of the operator is largely determined by the geometric relationship between the length of appropriate body segments, body position and the layout of the various components of the equipment. Other than segments length of the human body, the interference of the equipment elements with body segments and the visual requirements of the work also dictate the posture (Das et al. 2002).

Therefore, considering anthropometric data in the design and construction of hospital meal carts will go a long way in reducing the stress on both health workers and patients inclusive. Wetterneck et al. (2012) identifies the members of healthcare team to include physicians, nurses and other staff at the primary care clinic. Patients and families are also part of the medical home team. Hospital meal carts thus can be used by any of these medical team inferring that a wide range of people are vulnerable to musculoskeletal disorder from the use of hospital meal cart.

One of the factors that affect the usability of manual vehicles is the operational factor which is based on the anthropometry parameter of the user. Anthropometry is the science dealing with measurement of the size, weight and proportions of the human body (Saunders 2007). Collection of this information is often referred to as anthropometry data and is the basis for the size of button to the height of handrails. Such task is designed to accommodate both $5 \%$ tile and $95 \%$ tile height of car users. (Note: In this context, $5 \%$ tile represents a size where only $5 \%$ of the population is smaller; $95 \%$ tile represents a size where $5 \%$ are larger). Numerous other data sets contain 5 and $95 \%$ tile for a broad range of humans (Opeshaw and Taylor 2006).

Lin et al. (2006) reported that manual material handling (MMH) especially lifting represents a major occupational safety and health risk in places such as industries and hospitals. Musculoskeletal and low-back disorders are often attributed to over exertion of the body when the operator works to meet the demand of MMH tasks. Hence, the use of ergonomic principle in the design and evaluation of human work has been advocated and promoted in the workplace to minimize the occurrence of work-related musculoskeletal injuries (Sauter et al. 1991).

Das et al. (2002) worked on ergonomics evaluation and redesign of hospital meal cart and came up with recommendations for the design of hospital meal cart using the anthropometric data/principle of their region (Canada). The recommended designs for the hospital meal cart are basically the cupboard type, which are not common to Nigeria hospitals.

\section{Identifying the ergonomics and design problems of the hospital meal carts}

A structured questionnaire was developed for the purpose of identifying the ergonomic, design and other problems associated with the existing hospital meal carts (a copy of questionnaire is shown in "Appendix 1").Through direct observation and one-on-one interviews with experienced operators and supervisors, relevant information on task performance, equipment and working posture was obtained. Several factors affecting the use of the hospital meal carts such as maneuverability, strength required in operating the carts and others were considered and grouped 
into two major sections, namely operation and biomechanical sections.

(a) Operation section: Factors taken into consideration under this section are factors that associate directly with the operation of the cart which are the design factors. These factors are the ease of:

1. Getting the cart into motion;

2. Turning the cart while in motion;

3. Seeing over the cart;

4. Placing trays on the cart; and

5. Stopping the cart while in motion.

(b) Biomechanical section: This has to do with the level of discomfort experience by the workers as they make use of the conventional hospital meal carts as well as the overall rating of the job done. It considers the major part of the body that is involved in the operation of the carts. Some of the parts of the body considered include: neck; shoulder; arm; elbow; forearm; buttocks; wrist; hand; fingers; thigh; knee; leg; foot; upper back; and waist.

One hundred and fifty (150) questionnaires in all were administered in different sections of ten governmentowned hospitals in southwest of Nigeria and Abuja. Hospitals in Abuja were visited to serve as comparison with what is obtainable in the southwest of Nigeria so that a good sample of Nigeria situation can be obtained. Other hospitals visited were due to nearness and financial constraint. These hospitals captured in the course of questionnaire administration all render medical services to all tribes in Nigeria without discrimination. A total of one hundred (100) questionnaires which is $66 \%$ of the administered questionnaires were returned from the various hospitals. The remaining $33 \%$ were not attended to by respondents within the time frame. This is justified for this study based on the suggestion by Roscoe (1975) on sample size in statistics and research methodology, who suggested a sample size between 30 and 500 is appropriate for most research. Ninety-two (92) out of the one hundred (100) respondents were female, while the remaining eight (8) were male. The age of all the respondents ranges between 23 and 54 years, and their height ranges from 145.0 to $186.0 \mathrm{~cm}$. It was also observed that the respondents perform other functions within the hospital environment such as drugs administration, documentation and cleaning depending on the department within the hospital environment during the work shift which lasts for a minimum of eight (8) hours per day. Therefore, the operators do not perform the task of pushing and pulling of meal carts on a sustained basis but rather on a repetitive basis within short intervals depending on the department during the work shift.

\section{Analysis of the questionnaire}

The following steps were taken in analyzing the questionnaires:

1. Questionnaire coding: Values were attached to each of the expected answers the respondent picked from. Such as: no difficulty $=0$, slight difficulty $=1$, moderate difficulty $=2$, great difficulty $=3$, extreme difficulty $=4$.

2. Key in of data: The values from the coding were statistically analyzed using Statistical Package for the Social Sciences (SPSS).

3. Analysis: SPSS was then used to analyze the coded questions.

\section{Hospital meal cart evaluation}

The meal cart users in the various hospital visited were asked to attend to the questionnaire which serves as the tool for the ergonomic evaluation aiming at detecting whether the users experience any discomfort in using the meal carts as a result of the design of the carts and the overall description of rating of the work. The layout pathway of the meal carts needs a minimum space of $75.0 \mathrm{~cm}$ when moving forth or back and a minimum of $102.5 \mathrm{~cm}$ for turning the meal cart especially when in motion, while the meal carts are been pushed or pulled on smooth floor surfaces.

The responses obtained from ergonomic evaluation of the hospital meal carts were analyzed using SPSS to obtain the nonparametric Chi-square test as well as the median and interquartile range as described by Howitt and Cramer (1999). The results obtained are presented in Tables 1 and 2.

\section{Results and discussion}

Tables 1 and 2 show the result of the SPSS analysis of the responses obtained from the operational and biomechanical survey questionnaires used to carry out ergonomic evaluation of the hospital meal cart, and the tables show the median of the score, the interquartile range and the $p$ value obtained from the Chi-square analysis. The median score for the handle height placement while pushing was 3.00 (Table 1) which reflects that the positioning of the handle is of concern to the users as a larger category of the meal cart users experience great difficulty with the positioning of the handle while pushing the meal cart. The median score for the force used to stop the cart is 3.000 (Table 1) which 
Table 1 Operator scores obtained for operational survey of the conventional meal carts and Chi-square test for responses to the factors

\begin{tabular}{lllll}
\hline S/N & Design and other factors & Median & Interquartile range & Chi-square test: $p$ value \\
\hline 1 & Getting the four-wheel cart into motion & 0.000 & 0.000 & 0.090 \\
2 & Turning the four-wheel cart & 0.000 & 0.000 & 0.396 \\
3 & Seeing over the four-wheel cart & 1.000 & 1.000 & 0.258 \\
4 & Placing and removing trays & 0.000 & 0.000 & 0.572 \\
5 & Opening and closing doors & 0.000 & 0.000 & 0.258 \\
6 & Handle height (pushing) & 3.000 & 3.000 & 0.000 \\
7 & Handle height (Pulling) & 2.000 & 2.000 & 0.000 \\
8 & Force use to stop Cart & 3.000 & 3.000 & 0.020 \\
9 & Need for emergency brake & 1.000 & 1.000 & 0.001 \\
10 & Need for parking brake & 2.000 & 2.000 & 0.034 \\
11 & Overall work load & 4.000 & 4.000 & 0.090 \\
\hline
\end{tabular}

There is significant difference when $p<0.050$

Table 2 Discomfort scale scores for the body region of the conventional hospital meal cart and Chi-square test for response to the body region

\begin{tabular}{|c|c|c|c|c|c|c|c|}
\hline \multirow[t]{2}{*}{$\mathrm{S} / \mathrm{N}$} & \multirow[t]{2}{*}{ Body region } & \multicolumn{3}{|l|}{ Left } & \multicolumn{3}{|l|}{ Right } \\
\hline & & Median & Interquartile range & $\begin{array}{l}\text { Chi-square test: } \\
p \text { value }\end{array}$ & Median & Interquartile range & $\begin{array}{l}\text { Chi-square test: } \\
p \text { value }\end{array}$ \\
\hline 1 & Neck & 1.000 & 1.000 & 0.021 & 1.000 & 1.000 & 0.021 \\
\hline 2 & Upper back & 2.000 & 2.000 & 0.003 & 2.000 & 2.000 & 0.008 \\
\hline 3 & Shoulder & 1.000 & 1.000 & 0.000 & 2.000 & 2.000 & 0.013 \\
\hline 4 & Upper arm & 2.000 & 2.000 & 0.000 & 1.500 & 1.500 & 0.015 \\
\hline 5 & Mid-to-lower back & 1.000 & 1.000 & 0.011 & 1.000 & 1.000 & 0.000 \\
\hline 6 & Elbow & 1.000 & 1.000 & 0.072 & 1.000 & 1.000 & 0.126 \\
\hline 7 & Forearm & 1.000 & 1.000 & 0.034 & 1.000 & 1.000 & 0.037 \\
\hline 8 & Buttocks & 1.000 & 1.000 & 0.258 & - & - & - \\
\hline 9 & Wrist & 1.000 & 1.000 & 0.000 & 1.000 & 1.000 & 0.011 \\
\hline 10 & Hand & 0.000 & 0.000 & 0.777 & 0.000 & 0.000 & 0.572 \\
\hline 11 & Fingers & 1.000 & 1.000 & 0.157 & 1.000 & 1.000 & 0.258 \\
\hline 12 & Thigh & 1.000 & 1.000 & 0.001 & 1.000 & 1.000 & 0.002 \\
\hline 13 & Knee & 1.000 & 1.000 & 0.258 & 1.000 & 1.000 & 0.157 \\
\hline 14 & Lower leg & 1.000 & 1.000 & 0.001 & 1.000 & 1.000 & 0.000 \\
\hline 15 & Ankle or foot & 0.000 & 0.000 & 0.777 & 1.000 & 1.000 & 0.572 \\
\hline
\end{tabular}

There is significant difference when $p<0.050$

reflects that the users have concern for the high force needed to bring the cart to stop. The need for emergency brake also has a median score of 1.000 (Table 1) which reflects the response of the users agreeing to the need for emergency brake. Description of the overall workload at the end of the shift had a median value of 4.000 reflecting the users describing the work as hard. The median score of the remaining factors shows that they are of less concern to the users.

The Chi-square test (Table 1) revealed that there was a significant difference that is when $p<0.050$ in the responses of the users in the following design factors:

(a) Handle height placement while pushing $(p=0.000)$

(b) Handle height placement while pulling $(p=0.000)$ (c) Force use to stop the cart $(p=0.020)$

(d) Need for emergency brake ( $p=0.001)$

The effect of these design factors can be seen on the feelings felt by the users in the different regions of the body (Table 2).

The median score for feeling on the left upper back, left upper arm, right upper back and right shoulder was 2.000 revealing the pain or soreness on those regions of the body. The Chi-square test value showed that there was significant difference since $p<0.050$ in the response of the users to the level of discomfort experienced during the use of the existing hospital meal cart which shows that there is need for improvement in those regions of the body. The median score for feeling on the left shoulder, left mid-to-lower 
back, left forearm, right mid-to-lower back, right forearm, left wrist and right wrist was 1.000 (Table 2) reflecting slight pain or soreness. The Chi-square test also revealed significant differences since $p<0.050$ in the responses of the users to the level of discomfort experienced during the use of the existing hospital meal cart called for improvement. While the right forearm has a median score of 1.500 (Table 2) reflecting a range between the feeling of slight pain or soreness and the feeling of pain or soreness. Its Chisquare value revealed significant difference since $p<0.050$ in the responses of the users to the level of discomfort experienced during the use of the existing hospital meal cart. The feelings on the left wrist, right wrist, left thigh, right thigh, left lower leg and right lower leg show that the Chi-square value of the responses (Table 2) of users had significant difference since $p<0.050$ also to the level of discomfort experienced during the use of the existing hospital meal cart.

The feelings on the other body regions reveal no significant difference in the responses of the users (Table 2) to the level of discomfort experienced during the use of the existing hospital meal cart.

\section{Conclusion}

Based on the result obtained from the ergonomic evaluation of the hospital carts, the following conclusions are made:

1. The position of the handle is of concern to the users as the height is too high for most of the users which resulted in discomfort especially on the shoulder and upper back, hence the need for repositioning to accommodate both $5 \%$ tile users and $95 \%$ tile users.

2. The force required to bring the cart to stop is considered high for most users which also contribute to the feeling of discomfort on the upper arm and forearm, and this contributed to the quest of the users for a braking system in order to ease the halting of the cart.

3. A large percentage of the users of the hospital meal carts strongly agreed to the need for braking system in order to bring the cart to stop in case of emergency and to reduce the force required to bring the cart to stop.

The result also shows the need for ergonomic conformation in the design and fabrication of meal carts taking into cognizance the anthropometric data of this region. A question on repetitive strain injuries which was not covered in this research could be considered in the questionnaire for future work.

Acknowledgments The cooperation received from the management of the following hospitals visited were quite appreciated and acknowledged: National Hospital, Abuja; Wuse General Hospital, Abuja; Federal Medical Centre, Owo, Ondo State; General Hospital, Ilesha, Osun state; Wesley Guild Hospital, Ilesha, Osun state; General Hospital, Akure, Ondo State; Federal Medical Centre Ido, Ekiti State; and University of Ibadan Teaching Hospital, Oyo State.

Open Access This article is distributed under the terms of the Creative Commons Attribution License which permits any use, distribution, and reproduction in any medium, provided the original author(s) and the source are credited. 


\section{Appendix 1}

$\underline{\text { APPENDIX I }}$

HOSPITAL FOUR WHEEL CART ERGONOMIC SURVEY QUESTIONNAIRE

\section{BIODATA}
i. $\quad$ Name (Optional):
ii. $\quad$ Age: 15-25
26-35

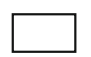
$36-59$

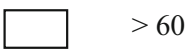
iii. Average Height:
iv. Work Section:
v. How long have you being doing this work:

\section{OPERATIONAL SURVEY}

The following questions have been developed to evaluate a number of factors associated with your four-wheel hospital carts. We would ask you to take a few moments and complete the questionnaire near the end of the work shift. For each question please chose the option which most closely represents your opinion about the factor under review. The results of this questionnaire will be kept confidential.

\section{KINDLY TICK AS APPROPRIATE}

i. $\quad$ Getting the four wheel cart in motion, I have:

ii. Turning the four - wheel cart, I have:

iii. Seeing over the four-wheel cart, I have:

iv. Placing and removing the trays, I have:

v. Opening and closing the doors, I have:

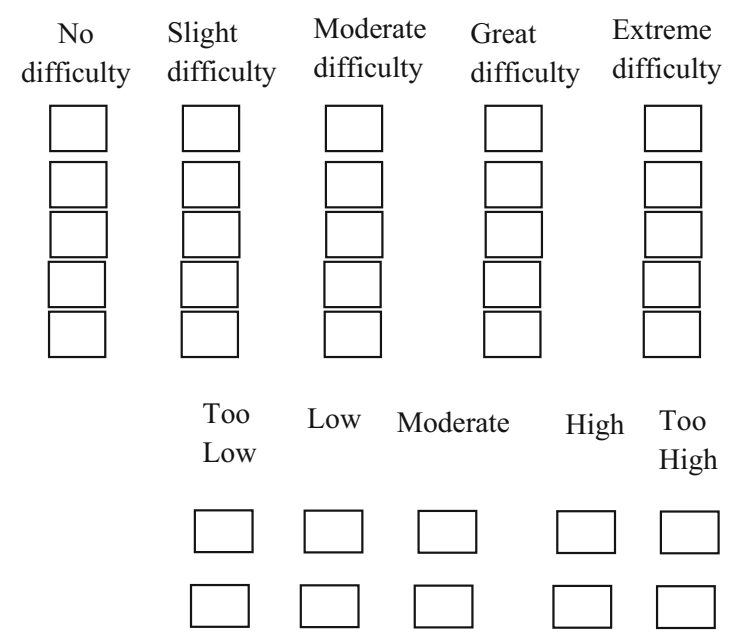

viii. When the four-wheel cart in motion, the force that I use to bring it to a stop

\section{KINDLY TICK AS APPROPRIATE}

ix. An emergency brake for the Panic stop would be useful:

x. A parking brake on the wheels would be useful:
Strongly Agree Neutral Disagree Strongly Agree
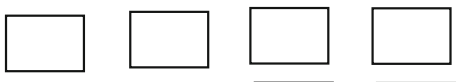
Disagree
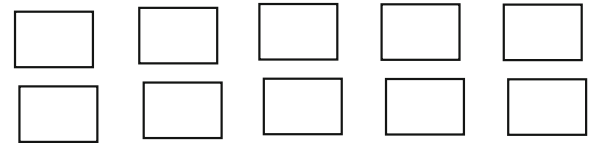


\section{BIOMECHANICAL SURVEY (Discomfort for Health Workers)}

As a result of performing your current task, rate the degree of discomfort for each body part according to the following scale:

0 : no feeling of pain and soreness 1: slight pain or soreness 2: pain or soreness

3: strong pain or soreness $\quad 4$ : extreme pain or soreness

\section{Put the most appropriate number in the boxes}

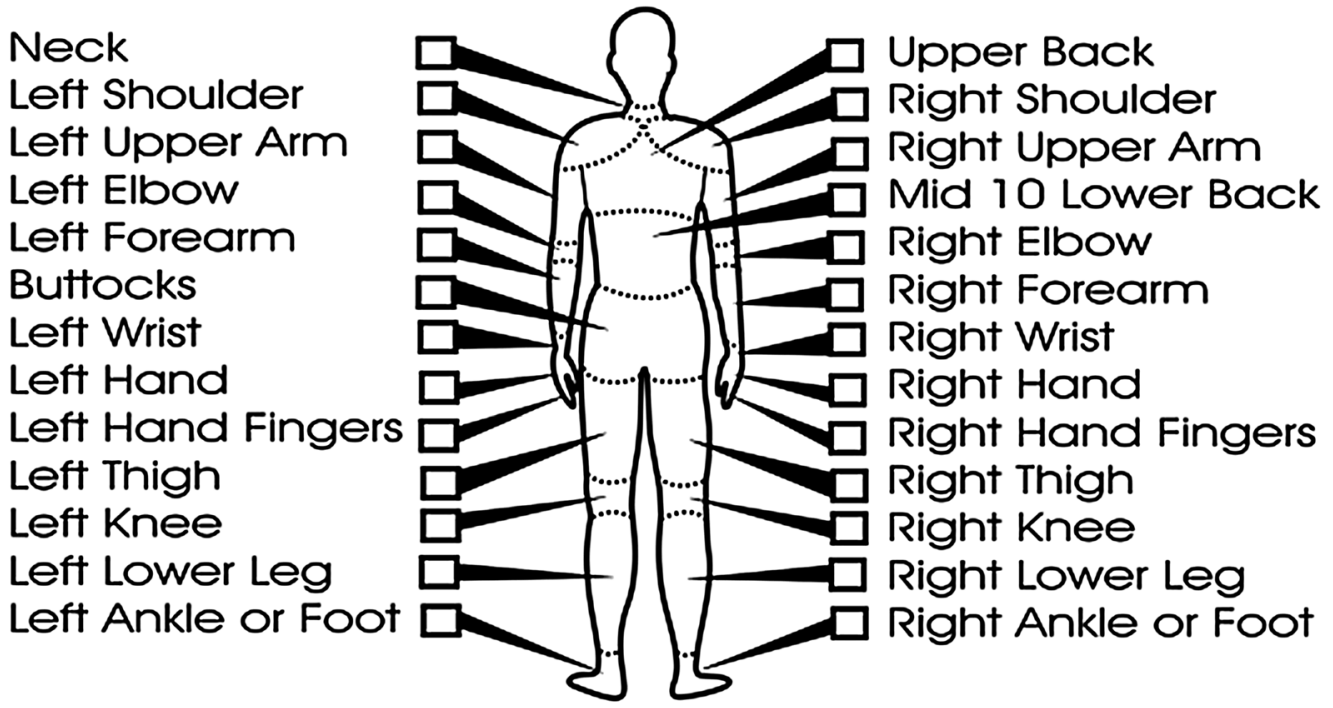

Rate the overall workload for the type of task(s) you performed

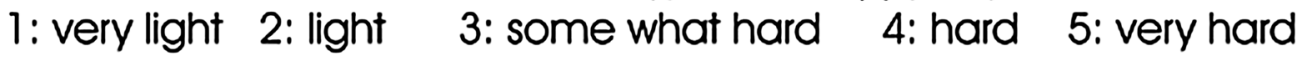

\section{References}

Beth L, Linda CB (2010) Ergonomics in the workplace, a resource guide. Accommodation and Compliance Series. Job Accommodation Network (JAN). A service of the Office of Disability Employment Policy of the U.S. Department of Labor

Das B, Wimpee J, Das B (2002) Ergonomics evaluation and redesigning of a hospital meal cart. Appl Ergonom 33(4):309-318

Health and Safety Executive (HSE) website (2010). www.hse.gov.uk/ Pubns/priced/18. Accessed 30 Nov 2013

Howitt D, Cramer D (1999) A Guide to computing statistics with SPSS Release 8 for Windows. Pearson Education Edinburgh Gate Harlow Essex CM20 2JE, England
Jung M, Haight JM, Freivalds A (2005) Pushing and pulling carts and two-wheeled hand trucks. Int J Ind Ergon 35:79-89

Lin CJ, Wang SJ, Chen HJ (2006) A field evaluation method for accessing whole body biomechanical joint stress in manual lifting tasks. Ind Health 44:604-612

Opeshaw S, Taylor E (2006) Ergonomics and Design; a reference guide. Allsteel Inc., Muscatine, Iowa

Roscoe JT (1975) Fundamental Research statistics for behavioural sciences, 2nd edn. Rinehart and Winston, New York

Saunders (2007) Dorlands's medical dictionary for health consumers, an imprint of Elsevier Inc. http://medicaldictionary.thefreedic tionary.com/anthropometry 
Sauter SL, Schleifer LM, Knutson SJ (1991) Work posture, workstation design and musculosketal discomfort in a VDT data entry task. Hum Factors 33:151-167

Schibyte BK, Sogaard D, Martinsen KK (2001) Mechanical load on the low back and shoulders during pushing and pulling twowheeled waste containers compared with lifting and carrying of bags and bins. Clin Biomech 16:549-559
Wetterneck TB, Lapin JA, Karch BT, Beasley JW (2012) Human factors and ergonomics in primary health care. In: Carayon $\mathrm{P}$ (ed) Handbook of human factors and ergonomics in health care and safety, $2^{\text {nd }}$ edn. Taylor and Francis Group, Boca Raton, pp 763-774 